\title{
Antibacterial titanium plate deposited by silver nanoparticles exhibits cell compatibility
}

This article was published in the following Dove Press journal:

International Journal of Nanomedicine

7 May 2010

Number of times this article has been viewed

Juan Liao'

Mo Anchun ${ }^{1,2}$

Zhimin Zhu ${ }^{3}$

Yuan Quan'

'State Key Laboratory of Oral Diseases, Sichuan University, Chengdu, PR China; ${ }^{2}$ Department of Dental Implant, ${ }^{3}$ Department of Prosthodontics; West China Stomatology Hospital, Sichuan University, Chengdu, PR China
Correspondence: Zhimin Zhu

West China College of Stomatology,

Sichuan University, No. 17, 3rd section,

Renmin Road, Chengdu, China 61004I

$\mathrm{Tel}+862885503571$

$\mathrm{Fax}+862885582167$

Email zzhimin@।63.com
Abstract: Microbial colonization and biofilm formation on the surface of implant devices may cause peri-implantitis and lead to bone loss. The aim of this study was to develop a novel antibacterial titanium implant surface and to test its biological performance. In a previous study, we demonstrated that titanium plates deposited by nanosilver acquired antibacterial activity to Staphylococcus aureus and Escherichia coli. While antibacterial activity is important, biomaterial surfaces should be modified to achieve excellent cell compatibility as well. In the present study, using the MTT assay, fluorescence microscopy, and scanning electron microscopy, we assessed cell viability, cytoskeletal architecture and cell attachment, respectively, on our silver nanoparticle-modified titanium (Ti-nAg) plate. The results demonstrate that the Ti-nAg do not show any cytotoxicity to the human gingival fibroblasts. Our data indicate that Ti-nAg is a novel material with both good antibacterial properties and uncompromised cytocompatibility, which can be used as an implanted biomaterial.

Keywords: nanosilver, titanium, antibacterial activity, cytocompatibility

\section{Introduction}

Titanium has been widely used as an implantable biomaterial, particularly as dental implants, since it has excellent corrosion resistance and biocompatibility. ${ }^{1,2}$ Multiple factors affect the outcome of dental implants, including osseointegration of bone implants and the degree of bacterial aggregation surrounding the implants. Because dental implants not only penetrate bone but also gingiva, they are partially exposed in an oral environment that includes oral bacteria. The transgingival abutment of the implant is an important portal of bacteria entry.

Previous studies have revealed that inflammatory diseases around the transgingival region of the implant might cause peri-implantitis and loss of supporting bone, which is associated with the reduction of long-term "survival" of implants. ${ }^{3}$ Therefore, it is important to prevent colonization of oral bacteria on the surfaces of implants to ensure their long-term clinical success.

Previously, we demonstrated that titanium (Ti) plates deposited by nanosilver acquired antibacterial activity. ${ }^{4}$ After 24 hours incubation, 94\% Staphylococcus aureus and more than $95 \%$ Escherichia coli were killed on the nanosilver-modified titanium surface (Ti-nAg). However, dental implants which are used in the oral cavity should also show antibacterial activity to oral bacteria. Furthermore, titanium implants applied in humans should be modified to exhibit excellent cell compatibility as well as antibacterial activity. It is generally believed that silver has natural cytotoxicity. 
As an extension of our previous study, we determined the cell compatibility of Ti-nAg surface in the current study.

In the present study, we examined the antibacterial and anti-adhesive property of Ti-nAg surface to oral bacteria. To evaluate the cell compatibility of Ti-nAg surface, we then examined the initial adhesion and proliferation of human gingival fibroblasts (hGFs) on Ti-nAg and control titanium surface.

\section{Materials and methods}

\section{Anti-bacterial tests}

Plates with Ti-nAg or Ti-polished surface were prepared as described previously. ${ }^{4}$ The antimicrobial activity of the Ti-nAg surface was tested against Porphyromonas gingivalis (Pg, ATCC33277; ATCC, Rockville MD) and Actinobacillus actinomycetemcomitans (Aa, ATCC43718). Film applicator coating (FAC) assay was used to test the antimicrobial effect by directly incubating microbial cells on Ti-nAg or polished titanium (Ti-polished) surfaces. In the FAC assay, concentration of each bacterial strain was adjusted to $1 \times 10^{7}$ cells $/ \mathrm{ml}$ in phosphate-buffered solution (PBS: NaCl $137 \mathrm{mmol} / \mathrm{L}, \mathrm{KCl} 2.7 \mathrm{mmol} / \mathrm{L}, \mathrm{Na}_{2} \mathrm{HPO}_{4}$ $4.3 \mathrm{mmol} / \mathrm{L}$, and $\mathrm{KH}_{2} \mathrm{PO}_{4} 1.4 \mathrm{mmol} / \mathrm{L}$ ). Titanium plates were placed on culture plates. $10 \mu \mathrm{l}$ bacterial suspension was added to Ti-nAg and Ti-polished plates, respectively, on which films were covered.

Following incubation in an anaerobic Petri dish at $37^{\circ} \mathrm{C}$ for 24 hours, the bacterial suspensions on the plate were separately transferred into tubes containing $10 \mathrm{~mL}$ sterilized PBS, followed by vigorous vortexing for $5 \mathrm{~min}$. $10 \mu \mathrm{L}$ bacteria were then added to solution from the mixture and was spread on blood agar plates containing trypticase soy agar supplemented with $10 \%$ defibrinated rabbit blood, hemin $(5 \mu \mathrm{g} / \mathrm{mL})$ and menadione $(0.5 \mu \mathrm{g} / \mathrm{mL})$, All of above reagents were obtained from Sigma-Aldrich (St. Louis, MO).

The plates were incubated anaerobically for 48 hours. The viable cells on each plate were counted by quantization of colony-forming units (CFU). Each colonization test was run in triplicate and repeated five independent times. The antibacterial effect in each group was represented by bactericidal ratio, which was calculated as follows:

bactericidal ratio $(\%)=[(\mathrm{CFU}$ of $\mathrm{CG}-\mathrm{CFU}$ of $\mathrm{EG}) / \mathrm{CFU}$ of $\mathrm{CG}] \times 100 \%$,

in which CFU is colony-forming unit; $\mathrm{CG}$ is Ti-polished specimen (control group); and EG is Ti-nAg specimen (experimental group).

\section{Antiadhesive test}

The antiadhesive activity of the Ti-Ag surface towards Pg and Aa were qualitatively evaluated by scanning electron microscopy (SEM; S-4800; Hitachi Tokyo, Japan). Ti-nAg and Ti-polished plates were immersed in $10 \mathrm{~mL}$ bacterial suspension, which contained $1 \times 10^{8}$ cells $/ \mathrm{mL}$ and cultured for 24 hours.

The loosened and detached bacterial cells were removed by dipping plates into sterile PBS. The plates were subsequently fixed with $2.5 \%$ glutaraldehyde solution for 2 hours.

After dehydration in an ethanol series $(30 \%, 50 \%, 70 \%$, $80 \%, 90 \%$, and $100 \%$, respectively), the ethanol was replaced by amyl acetate solution for 1 hour at room temperature, which was then critical-point dried. The resultant plates were coated with $8 \mathrm{~nm} \mathrm{Au}$ in a sputter coater and visualized for remaining bacterial cells with SEM.

\section{Cytocompatibility assays}

Human gingival fibroblasts (hGFs) (4th passage) in exponential growth phase were used for the cytocompatibility test. Cells were cultured in $\alpha$ minimal essential medium (HyClone, Thermo Fisher Scientific Inc Waltham, MA) containing 10\% fetal bovine serum (Gibco) and 1\% antibiotic (penicillin, Gibco, Carlsbad, CA) under a $5 \% \mathrm{CO}_{2}$ atmosphere at $37^{\circ} \mathrm{C}$. The experiment contained two groups: Ti-nAg (A) and Ti-polished (B). The titanium plates of each group were placed into 24-well plates, respectively. hGFs were seeded onto each group in 24 -well plates at a density of $2 \times 10^{4}$ cells $/ \mathrm{mL}$. After $1,2,4$, 6 , and 8 days, the MTT assay was performed and the OD for each group was determined.

Cell morphology and cytoskeletal architecture was observed by fluorescence microscopy. Specimens were placed in 24-well culture plates with $1 \mathrm{~mL}$ cell suspension. The density of cells was $5 \times 10^{4}$ cells $/ \mathrm{mL}$. Subsequently, the specimens were incubated at $37^{\circ} \mathrm{C}$ in $5 \% \mathrm{CO}_{2}$ for 24 hours. Adherent cells on each specimen after 24 hours of cultivation were washed with PBS . The cells were fixed with $4 \%$ paraformaldehyde in PBS and permeabilized with $0.2 \%$ Triton X-100 (Sigma) in PBS for $15 \mathrm{~min}$ at room temperature. The cells were then incubated for 1 hour in a FITC-conjugated Phalloidin solution (1:300; Sigma) at room temperature.

After the cells were washed with PBS, they were examined under fluorescence microscope (Leica DMI 6000 B; Lecia, Wetzlar, Germany).

Cell attachment and proliferation were determined by SEM. hGFs were seeded at a density of $5 \times 10^{4} \mathrm{cell} / \mathrm{mL}$ and SEM photomicrographs after 3-hour and 12-hour incubations were taken for visualization. 
A

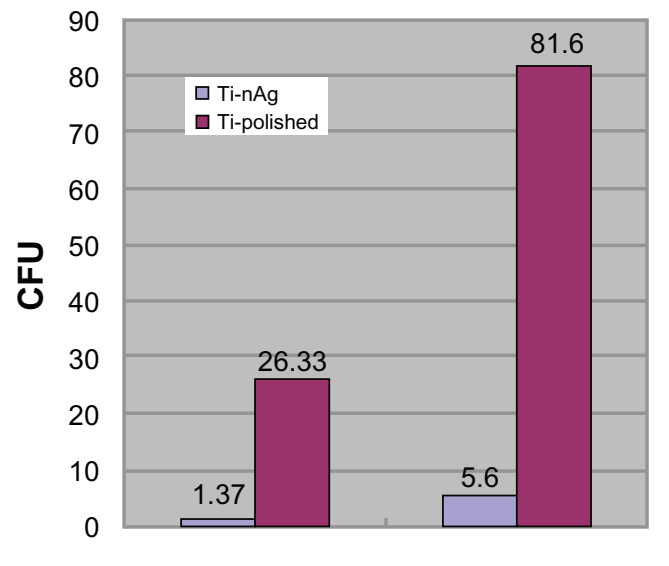

B

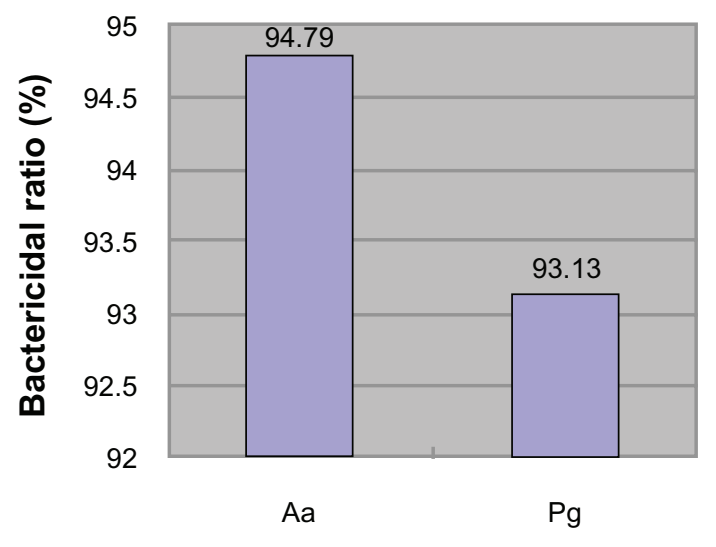

Figure I Inhibition of bacterial growth on Ti-nAg surface. A) The colony-forming units (CFU) of $\mathrm{Pg}$ and $\mathrm{Aa}$ on Ti-nAg and Ti-polished surface after 24-hour incubation. B) The bacterial ratio of $\mathrm{Pg}$ and $\mathrm{Aa}$ on $\mathrm{Ti}-\mathrm{nAg}$ surface in relation to Ti-polished surface.

\section{Statistical analysis}

Each group was respectively compared, using independent Student's $t$-test. For all statistical analyses, the probability of type I error less than or equal to 0.05 was considered as statistically significant. Each test was run in triplicate and repeated at three separate times.

\section{Results}

\section{Antimicrobial and anti-adhesive properties}

Since Pg and the Aa have been reported to be the major periodontopathic bacteria, ${ }^{5,6}$ these two bacterial strains were used to test antimicrobial and antiadhesive properties of Ti-Ag surface. Specifically, we adopted FAC tests to determine antibacterial activities and use SEM to observe antiadhesive activities of the Ti-nAg surface. In the FAC assay, the Ti-nAg surface exhibited a strong antibacterial property.

Following 24 hours incubation, $94.79 \% \mathrm{Aa}$ and $>93 \% \mathrm{Pg}$ of bacteria in suspension were inhibited on the Ti-nAg surface (Figure 1). The SEM of Ti-nAg and Ti-polished specimens incubated with Pg or Aa are shown in Figures 2 and 3, respectively. The adhesion of both Pg and Aa was markedly decreased on the Ti-nAg surface, compared to the Ti-polished surface. The morphology of the Aa adhered to the surface showed an aggregated appearance, while the Pg was dispersed.

\section{Cytocompatibility assays}

\section{Cell viability assay}

Using the MTT test, HGF viability was assessed after 1, 2, 4, 6, and 8 days of incubation. The values of OD for the five groups
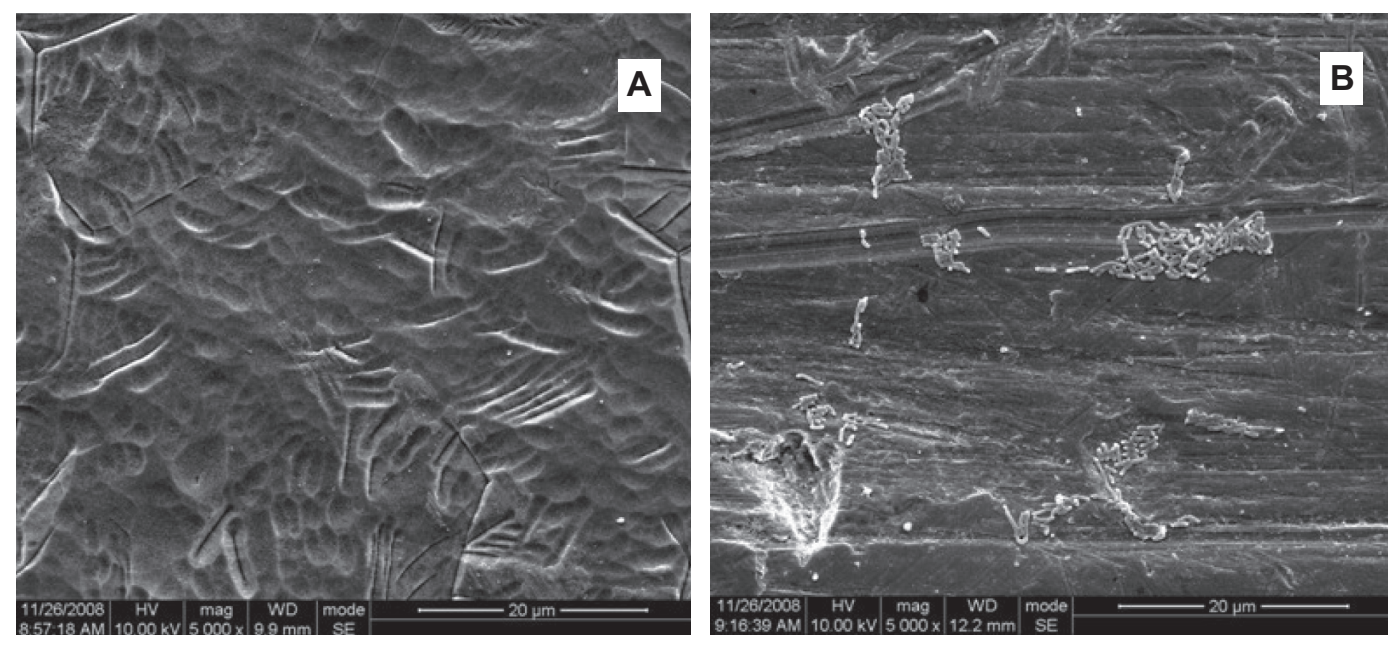

Figure 2 Scanning electron photomicrographs of the Ti-nAg (A) and Ti-polished (B) surfaces after incubation of Aa (magnification: $5000 \times$; working distance: $8000 \mu$ m). The Aa bacteria exhibited a rod shape and reduced bacterial attachment to the Ti-nAg surface, relative to the Ti-polished surface. 

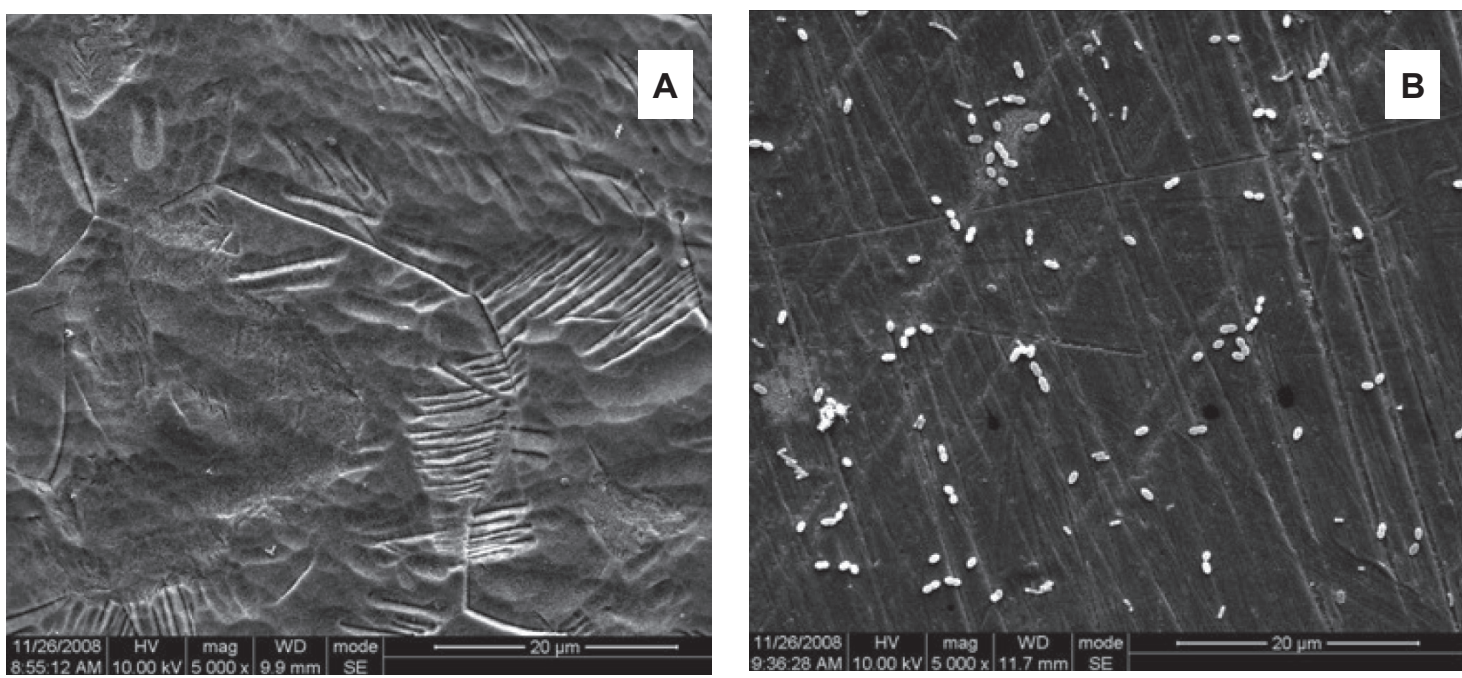

Figure 3 Scanning electron photomicrographs of the $\mathrm{Ti}-\mathrm{nAg}(\mathbf{A})$ and Ti-polished (B) surfaces after incubation of Pg (magnification: $5000 \times$; working distance: $8000 \mu \mathrm{m}$ ). The Pg bacteria exhibited a round shape and reduced bacterial attachment to the Ti-nAg surface, relative to the Ti-polished surface.

are shown in Figure 4. The OD of the first four groups increased gradually from day 1 through day 5 and reached a peak at day 6 , followed by a decrease at day 8 . Statistical analysis did not reveal significant differences among the five groups $(P>0.05)$.

\section{Cell morphology and cytoskeleton}

Images of fluorescent staining for cytoskeletal architecture are shown in Figure 5. hGFs exhibited a fusiform or polygonal shape and microfilaments of the cells were obvious. The cell morphology and cytoskeleton were similar between the two groups of culture.

\section{Attachment and proliferation of hGFs}

hGFs had begun to attach to the Ti surface after 3-hour culture (Figures 6A and 6B). The cells were round, fusiform or polygon shape. The quantity of the cells was small and some of them had started to spread. After 12-hour culture (Figures 6C and 6D), cells appeared to form contacts with adjacent fibroblasts and started to align and appeared elongated, flat and intimately attached to the surface. Cells spread well, indicating good attachment to these surface.

\section{Discussion}

From a clinical perspective, antibacterial materials for dental implants should meet at least two important criteria: effective in reducing infection rate; and must not have cytotoxic effects in the human body. The current study was performed to evaluate the two properties of Ag-Ti materials in vitro before it is applied for clinical purposes.

Bacterial adhesion to medical devices is the first step in the development of infections on abiotic surfaces. ${ }^{7}$ Once bacteria attach to a medical device, a multistep process will occur and ultimately lead to formation of biofilm. Because the bacteria on the interior of the biofilm are protected from phagocytosis and antibiotics, they are far more resistant to ordinary antimicrobial therapy. ${ }^{8,9}$ Therefore, it is important to modify the surface of the materials to prevent the primary attachment of bacteria. Using SEM, we examined antiadhesive activities of the Ti-nAg surface. Out results indicate that there were much less bacteria adherent to Ti-nAg surface, relative to the Ti-polished surface after 24 hours of incubation.

The inhibition of the growth and expansion of bacteria attaching to the surface is another important mechanism of reducing formation of biofilm. ${ }^{10}$ Therefore, while inhibiting the primary adhesion of oral bacteria to surfaces, it is also necessary to ensure that implants possess antibacterial activity.

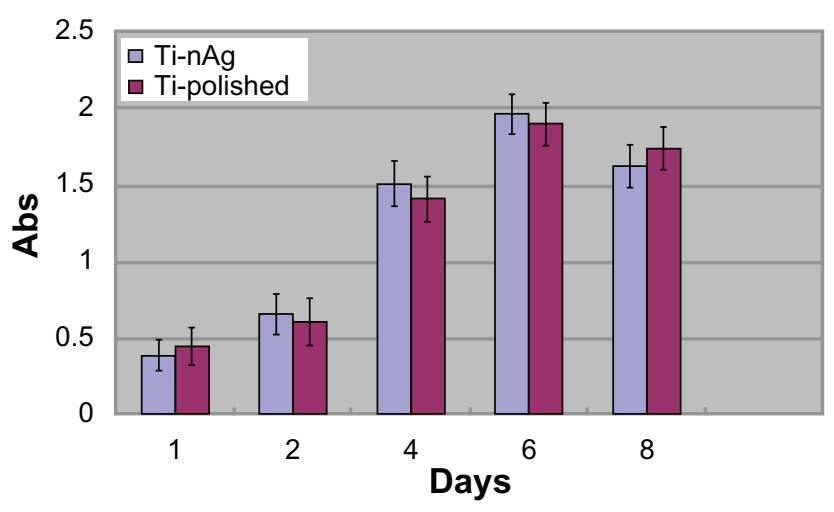

Figure 4 Cell viability estimated by the MTT assay after a 1-, 2-, 4-, 6- and 8-day incubation. Open bars represent the $\mathrm{Ti}-\mathrm{nAg}$ group. The solid bars represent the Ti-polished group. No significant differences were observed between Ti-polished and Ti-nAg specimens. 

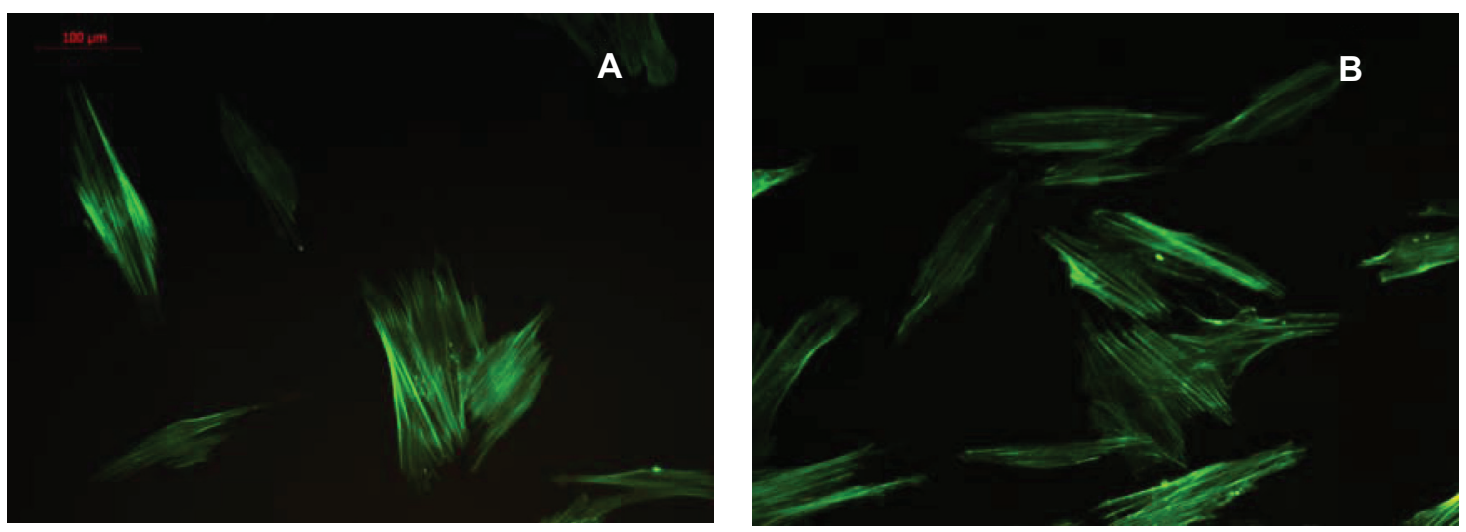

Figure 5 Fluorescence microscopy of adherent HGFs on plates with a Ti-nAg surface $(\mathbf{A})$ or Ti-polished surface (B). HGFs exhibited a fusiform or polygonal spreading shape. No significant differences of cell morphology and cytoskeletal architecture were observed between Ti-polished and Ti-polished specimens.

Using the FAC test, we further determined the antibacterial activities of the Ti-nAg surface. The results of the test show that the Ti-nAg surface had strong antibacterial properties. The antibacterial mechanism of Ti-nAg surface attributes to the silver nanoparticles and release of silver ions.

Because of the three-dimensional exposure of nanoparticle on the Ti surface, the silver nanoparticles provide an extremely large surface area available for interaction with bacteria from all directions, which provides better contact with microorganisms and enhanced antibacterial activity.
The nanoparticles attach to the cell membrane and also penetrate bacteria. ${ }^{11}$ It has been demonstrated that the silver nanoparticles cause bacterial inactivation and prevent bacterial replication in vitro by binding to microbial DNA and to the sulfhydryl groups of the metabolic enzymes in the bacterial electron transport chain. ${ }^{12}$ The nanoparticles release silver ions in aqueous solution, which further enhances the bacteriacidal activity, ${ }^{13}$ since $\mathrm{Ag}^{+}$strongly binds to electron donor groups in biological molecules containing sulfur, oxygen or nitrogen. ${ }^{14}$
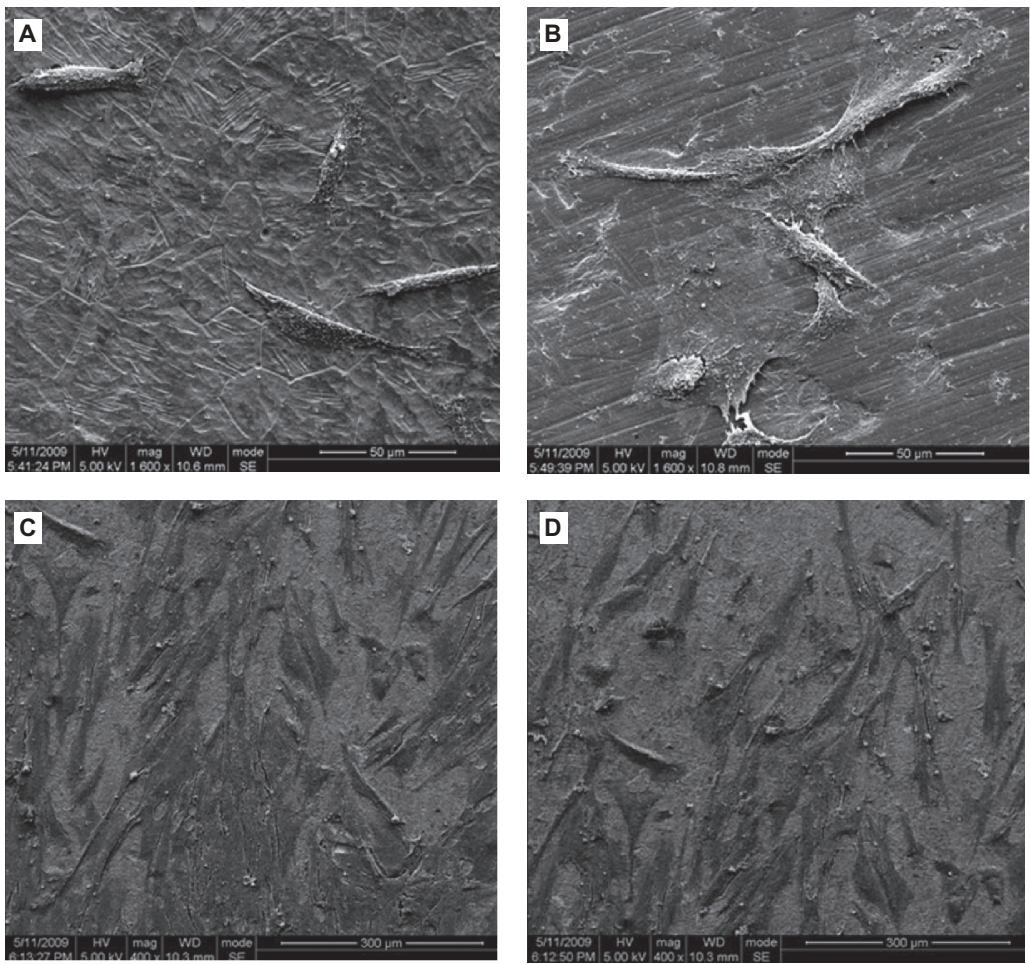

Figure 6 Scanning electron photomicrographs of human gingival fibroblasts (hGFs) cultured for $3 \mathrm{~h}$ (A, B) and I2 h (C, D) on plates with Ti-nAg (A, C) or Ti-polished (B, D) surfaces. The hGFs cultured on each surface underwent some proliferation, while maintaining normal spreading morphology. There was no obvious difference between the two surface groups. 
However, it is believed that silver has cytotoxicity to human tissue at certain concentrations. ${ }^{15}$ In our experiment, the hGFs were used to assess cell toxicity by cell morphological evaluation and cell activity test. In the MTT assay, hGF growth was not inhibited on Ti-nAg compared with the Ti-polished surface. The fluorescent staining of the cell cytoskeleton suggests the cell morphology was not affected by the modified surface. SEM examinations also showed that cells on modified surface maintained a normal architecture. These results suggest that the Ti-nAg plates do not show detectable cytotoxicity to hGFs.

Eukaryotic cells are usually larger than prokaryotic cells and exhibit a far bigger target for attacking silver ions. Eukaryotic cells show more structural and functional redundancy compared to prokaryotic cells. Thus, higher silver ion concentrations are required to achieve comparable toxic effects, relative to bacterial cells. ${ }^{16}$ In our experiment, the silanization method was used for depositing silver nanoparticles on titanium surfaces, while the nanosilver concentrations of the Ti surface depended on the immersion time and the concentration of the nanosilver. ${ }^{4}$ The nanosilver concentration on the Ti-nAg surface, which was prepared by immersion into $0.25 \mathrm{mM}$ nanosilver solution for 3 hours, was an appropriate "therapeutic window" that was effective for attacking the bacteria, while not sufficient to produce harmful effects on eukaryotic cells.

In summary, the nanosilver-modified Ti surface has excellent antibacterial activity and minimal cytotoxicity on cultured hGFs and may be used as an implantable biomaterial.

\section{Conclusion}

In the present study, using the FAC assays and antiadhesive tests, we determined antibacterial and antiadhesive activities of a silver nanoparticle-modified titanium surface, which was prepared using the silanization method.

Our data indicate that the Ti-nAg surface has remarkable antibacterial and antiadhesive activities to Pg and Aa bacterial cells.

In addition, the modification of $\mathrm{Ti}$ surfaces with nanosilver did not show detectable cytotoxicity on cultured
hGFs. Collectively, Ag-Ti surface has obvious antibacterial activities and excellent cell compatibility.

These data suggest that Ti-nAg is a promising material with antibacterial properties and can be used as an implantable biomaterial.

\section{Disclosure}

The authors report no conflicts of interest in this work.

\section{References}

1. Gronowicz G, McCarthy MB. Response of human osteoblasts to implant materials: integrin-mediated adhesion. J Orthop Res. 1996;14: 878-887.

2. Howlett CR, Evans MD, Walsh WR, Johnson G, Steele JG. Mechanism of initial attachment of cells derived from human bone to commonly used prosthetic materials during cell culture. Biomaterials. 1994;15:213-222.

3. Esposito M, Hirsch J, Lekholm U, Thomsen P. Biological factors contributing to failures of osseointegrated oral implants.(II) Ktiopathogenesis. Eur I Oral Sci. 1998;106:721-764.

4. Liao JZZ, Anchun M. Deposition of silver nanoparticles on titanium surface for antibacterial effect. Int J Nanomedicine. 2010;5:261-267.

5. Leonhardt A, Renvert S, Dahlen G. Microbial findings at failing implants. Clin Oral Implants Res. 1999;10:339-345.

6. Listgarten MA, Lai CH. Comparative microbiological characteristics of failing implants and periodontally diseased teeth. J Periodontol. 1999;70:431-437.

7. Boland T, Latour RA, Sutzenberger FJ. In: An YH, Friedman RJ, (Editors), Handbook of Bacterial Adhesion: Principles, Methods, and Applications. Totowa, NJ: Humana Press; 2000:29.

8. Pearce D, Bazin MJ, Lynch JM. In: Lappin-Scott HM, Costerton JW, (Editors). Microbial Biofilms. New York, NY: Cambridge University Press; 1995:207.

9. Jeyachandran YL, Narayandass SK, Mangalaraj D, Bao CY, Li W, Liao YM. A study on bacterial attachment on titanium and hydroxyapatite based films. Surface and Coatings Technology. 2006;201:3462-3474.

10. Yoshinari M, Oda Y, Kato T, Okuda K. Influence of surface modifications to titanium on antibacterial activity in vitro. Biomaterials. 2001;14:2043-2048.

11. Rai M, Yadav A, Gade A. Silver nanoparticles as a new generation of antimicrobials. Biotechnology Advances. 2009;27:76-83.

12. Darouiche RO. Anti-infective efficacy of silver-coated medical prostheses. Clin Infect Dis. 1999;29:1371-1377.

13. Morones JR, Elechiguerra JL, Camacho A, Ramirez JT. The bactericidal effect of silver nanoparticles. Nanotechnology. 2005;16:2346-2353.

14. Song HY, Ko KK, Oh LH, Lee BT. Fabrication of silver nanoparticles and their antimicrobial mechanisms. Eur Cells Mater. 2006;11:58.

15. Braydich-Stolle L, Hussain S, Schlager J, Hofmann MC. In vitro cytotoxicity of nanoparticles in mammalian germ line stem cells. Toxicol Sci. 2005;88:412-419.

16. Alt V, Bechert T, Steinrucke P, Wagener M, Seidel P. An in vitro assessment of the antibacterial properties and cytotoxicity of nanoparticulate silver bone cement. Biomaterials. 2004;25:4383-4391.

International Journal of Nanomedicine

\section{Publish your work in this journal}

The International Journal of Nanomedicine is an international, peerreviewed journal focusing on the application of nanotechnology in diagnostics, therapeutics, and drug delivery systems throughout the biomedical field. This journal is indexed on PubMed Central, MedLine, CAS, SciSearch $\AA$, Current Contents $₫ /$ Clinical Medicine,

Submit your manuscript here: http://www.dovepress.com/international-journal-of-nanomedicine-journal

Journal Citation Reports/Science Edition, EMBase, Scopus and the Elsevier Bibliographic databases. The manuscript management system is completely online and includes a very quick and fair peer-review system, which is all easy to use. Visit http://www.dovepress.com/ testimonials.php to read real quotes from published authors. 